\title{
$\beta$-hexanitrohexaazaisowurtzitane Particles Prepared by Spray Drying and its Characterization
}

\author{
Wenzheng XU *, Hao LI, Xin LIANG, Jie WANG, Jinyu PENG, Jingyu WANG \\ School of Environment and safety engineering, North University of China, No. 3 XueYuan Rd. JianCaoPing District, \\ Taiyuan 030051, P. R. China \\ crossref http://dx.doi.org/10.5755/j02.ms.22853
}

Received 01 March 2019; accepted 06 May 2019

\begin{abstract}
In this paper, the ultrafine $\beta$-hexanitrohexaazaisowurtzitane $(\beta-C L-20)$ particles were prepared by spray drying method. The CL - 20 samples were characterized by scanning electron microscope (SEM), particle size analyzer, X-ray diffraction (XRD), and Differential Scanning Calorimeter (DSC). Furthermore, the safety properties of samples under impact and thermal stimulus were tested and analyzed. The results of SEM showed that the average particle size of ultrafine CL-20 particles with a narrow particle size distribution, were about $320 \mathrm{~nm}$, and the shape was elliptical. The XRD patterns indicated that the polymorphic phase of ultrafine particles was mainly $\beta$-type. Compared with that of raw $C L-20$, the impact sensitivity of the ultrafine $\mathrm{CL}-20$ had been decreased significantly, for the drop height (H50) was increased from 13.0 to $33.5 \mathrm{~cm}$. The critical explosion temperature of the ultrafine $\mathrm{CL}-20$ decreased from $232.16{ }^{\circ} \mathrm{C}$ to $227.93{ }^{\circ} \mathrm{C}$, indicating that the thermal stability of the ultrafine $\mathrm{CL}-20$ is lower than that of raw $\mathrm{CL}-20$.

Keywords: ultrafine $\mathrm{CL}-20$, spray drying, spherical, thermal stability, impact sensitivity.
\end{abstract}

\section{INTRODUCTION}

2, 4, 6, 8, 10, 12-Hexanitro-2, 4, 6, 8, 10, 12 hexaazaisowurtzitane, which was considered as the promising substitute of common energetic materials due to its high detonation velocity and energy density [1-3], was firstly synthesized by Nielsen et al in 1987 [4]. It is well known, $\mathrm{CL}-20$ was used as additional component with high energy in solid propellant [5-7], NEPE [8] and mixed explosives [9-11]. Meanwhile, it was expected to be wildly used in military and business aspect [12]. Besides, $\mathrm{CL}-20$ was able to be used to explore new formulas and product $[13,14]$. However, $\mathrm{CL}-20$ could not have many practical applications due to its high mechanical sensitivity. Thus, how to obtain a kind of reduced sensitivity of CL -20 with fine explosive ability had attracted wide attention. Generally, one of the effective approaches to achieve this purpose was reducing the particle size of crystals. The $\mathrm{CL}-20$ with smaller size was more insensitive since its crystal contained smaller quantity of defects and inclusions. When the $\mathrm{CL}-20$ with nanoscale was obtained, its sensitivity would be lower than that of raw $\mathrm{CL}-20$. So how to prepare $\mathrm{CL}-20$ with reduced sensitivity was the focus in the field of high density energetic materials [15].

In recent years, many methods were involved to prepare energetic materials with high performance, suchas solvent-nonsolvent recrystallization [16], micron-emulsion [17] and milling [18]. Those methods were valuable to obtain ultrafine crystal particles, but there were some disadvantages. Milling was a formal way to obtain the particle with lower size. But it might create the defects on the surface of crystal, which was not recommended for the preparation of nanoscale energetic material.When microemulsion method was used to prepared nano-CL -20 , it might lead to the complication of progress after experiment. The $\mathrm{CL}-20$ prepared by the solventnonsolvent recrystallization method had higher surface energy, but it showed the unstable thermal properties and the tendency of cluster.

Spraying techniques were used to prepare nanomaterial particles [19-21]. In this paper, spray drying was performed using a reflux condenser and a nebulizer. Using a nebulizer to atomize explosive solution to form fog droplets, and the fog droplets were sprayed into the inner core of the reflux condenser. The hot water was circulated by a constant temperature water bath through the outer core of the reflux condenser, then the solvent in the fog droplets evaporates to get the ultrafine $\mathrm{CL}-20$ particles. The particles size and morphology of the $\mathrm{CL}-20$ particles obtained were characterized, and the thermal stability and the mechanical sensitivity were tested and analyzed.

\section{EXPERIMENT}

\subsection{Materials}

Raw CL -20 was provided by Liaoning Qingyang Special Chemicals Co., Ltd., China. Acetone, Ethyl acetate and Methyl acetate (AR grade) were purchased from Tianjing Hengxing Chemical Reagent Company.

\subsection{Experimental setup and progress}

The device of spray drying is shown in Fig. 1. It consists of a nebulizer, a reflux condenser, a circulating water bath, a cyclone separator, a collection device, a pressure control valve, and an air compressor. Fig. 2 shows the process mechanism for the preparation of ultrafine $\mathrm{CL}-20$ particles by spray drying. The principle of spray

\footnotetext{
${ }^{*}$ Corresponding author. Tel.: +86-135-1361-5001.

E-mail address: xuwznuc@126.com (W. Xu)
} 
drying can be described as follows: About $1 \mathrm{~g}$ raw $\mathrm{CL}-20$ was dissolved in solvent, and the solution of $\mathrm{CL}-20$ was poured into the. Meanwhile, the air compressor and the pressure control valve were turned on and the input air pressure of the air compressor was adjusted. Then the fog droplets of explosive solution were formed and sprayed from the nebulizer. When the fog droplets passed through the the inner core of the reflux condenser, the solvent evaporated rapidly. Finally, the particles of the ultrafine $\mathrm{CL}-20$ were collected in the collection device after passing through the cyclone separator.

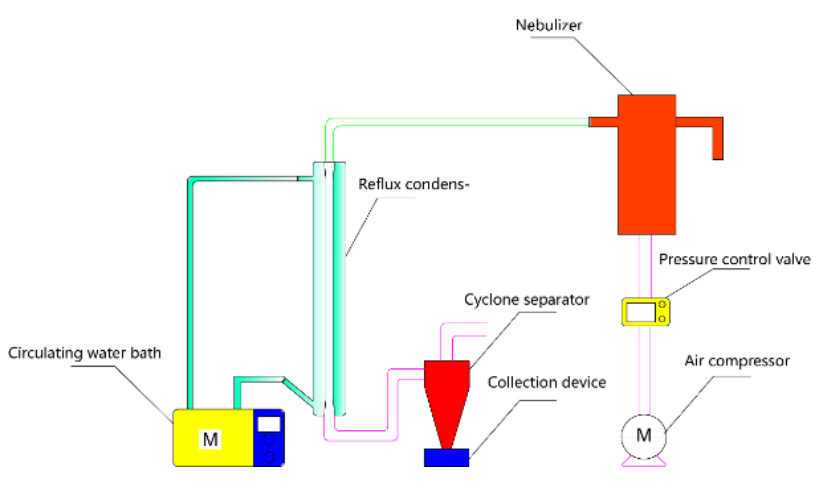

Fig. 1. Spray drying device

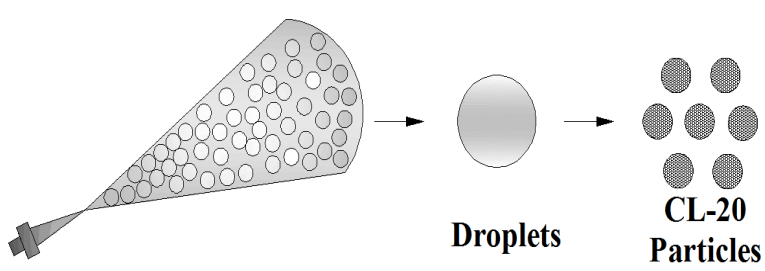

Fig. 2. The process mechanism of spray drying

\subsection{Characterization}

S4800 field - emission scanning electron microscope was used to characterize particle size and morphology of raw $\mathrm{CL}-20$ and the sample prepared. The equipment was manufactured by Hitachi Limitedin Japan.

The BI-90 PLUS particle size analyzer was used to test the sample of $\mathrm{CL}-20$ particle size distribution and median particle size. It was manufactured by the United States Brookhaven Corporation.

The X-ray diffractometer was used to identify raw $\mathrm{CL}-20$ and the sample prepared. It was manufactured by China Dandong Haoyuan Instrument Co., Ltd. Testing conditions included target material $(\mathrm{Cu})$ with tube voltage of $40 \mathrm{kV}$, tube current of $30 \mathrm{~mA}$, a $5^{\circ}$ start angle, and $50^{\circ}$ end angle.

Differential scanning calorimetry (DSC) was carried out with Setaram DSC 131 instrument, which was made by Setaram of France. In the test, each $0.5 \mathrm{mg}$ sample was placed in closed aluminum crucible with $30 \mu \mathrm{L}$ volume and holes in lid. The samples were measured with temperature profile of $30{ }^{\circ} \mathrm{C}$ to $300{ }^{\circ} \mathrm{C}$ and heating rate of 5,10 , $20{ }^{\circ} \mathrm{C} / \mathrm{min}$ in nitrogen atmosphere and flow of $30 \mathrm{~mL} / \mathrm{min}$.

ERL type 12-drop hammer apparatus was used to conduct impact sensitivity test according to GJB-772A-97 standard method 601.3 [22]. Testing conditions consisted of drop weight of $2.500 \pm 0.002 \mathrm{~kg}$, sample mass of $35 \pm 1 \mathrm{mg}$, and relative humidity of $50 \%$. The test results were represented by critical drop height of $50 \%$ explosion probability (H50).

\section{RESULTS AND DISCUSSION}

\subsection{Influencing factors}

In this study, a single control variable method was used to discuss the three influencing factors: solvent type, evaporation temperature, and solution concentration. The spray rate was constant at $2 \mathrm{ml} / \mathrm{min}$.

\subsubsection{Solvent type}

In this study, water bath heating method was used, so the boiling point of the chosen solvent should be lower than the boiling point of water $\left(100^{\circ} \mathrm{C}\right)$. According to reference acetone, ethyl acetate, and methyl acetate were chosen as solvents. The solubility of CL -20 in different solvents and the boiling point of solvents are shown in Table 1.

Table 1. Solubility of CL-20 in different solvents and solvent boiling point

\begin{tabular}{|l|c|c|}
\hline \multicolumn{1}{|c|}{ Solvent } & Solubility, $\mathrm{g} / 100 \mathrm{ml}$ & Boiling point, ${ }^{\circ} \mathrm{C}$ \\
\hline Acetone & 74.8 & 58 \\
\hline Ethyl acetate & 40.6 & 77 \\
\hline Methyl acetate & 50.35 & 58 \\
\hline
\end{tabular}

To study the effect of the solvent, the solution concentration was $5 \%$, the acetone system temperature was $60{ }^{\circ} \mathrm{C}$, the ethyl acetate system temperature was $80{ }^{\circ} \mathrm{C}$, and the methyl acetate system temperature was $60^{\circ} \mathrm{C}$. Scanning electron microscopy (SEM) was used to characterize the morphology of $\mathrm{CL}-20$ samples. The results are shown in Fig. 3.

As shown in Fig. 3, when the solvent is acetone, themorphology of CL-20 crystal is the best, the particle size distribution is narrow and the surface is smooth and non-angular. When the solvent is ethyl acetate, the crystals are spherical with a few holes on the surfaces, and the particle size distribution is uneven. When the methyl acetate is used as the solvent, the crystal morphology of $\mathrm{CL}-20$ is not good, and there is a slight agglomeration phenomenon with holes on the surfaces of CL-20 particles, but the particle size distribution is relatively uniform.

As a result, acetone was used as a solvent in the next study.

\subsubsection{Temperature}

To study the effect of temperature, acetone was used as the solvent and the solution concentration was $5 \%$. The temperatures were $60{ }^{\circ} \mathrm{C}, 75^{\circ} \mathrm{C}$, and $90{ }^{\circ} \mathrm{C}$, respectively. SEM was used to characterize the morphology of CL-20 samples. The results are shown in Fig. 4.

As shown in Fig. 4, CL-20 particle size distribution at a temperature of $60{ }^{\circ} \mathrm{C}$ is wider than that of $\mathrm{CL}-20$ at $75^{\circ} \mathrm{C}$ and $90^{\circ} \mathrm{C}$, and the particle size is larger. The difference between the particles obtained at the temperature of $75^{\circ} \mathrm{C}$ and $90^{\circ} \mathrm{C}$ is not significant, the particles are spherical with smooth surfaces and the size distributions are uniform. The 
reasons were as follows: when the temperature is $60^{\circ} \mathrm{C}$, the solvent in the droplets could not be volatilized, resulting in mutual collision and agglomeration in the atomization and drying. Acetone was volatilized rapidly at $75^{\circ} \mathrm{C}$ and $90{ }^{\circ} \mathrm{C}$. Meanwhile, the reaction was instantaneously completed at the interfaces with the droplets, and the crystals grew in the droplets. During this process, there were mutual collision and agglomeration in the droplets.
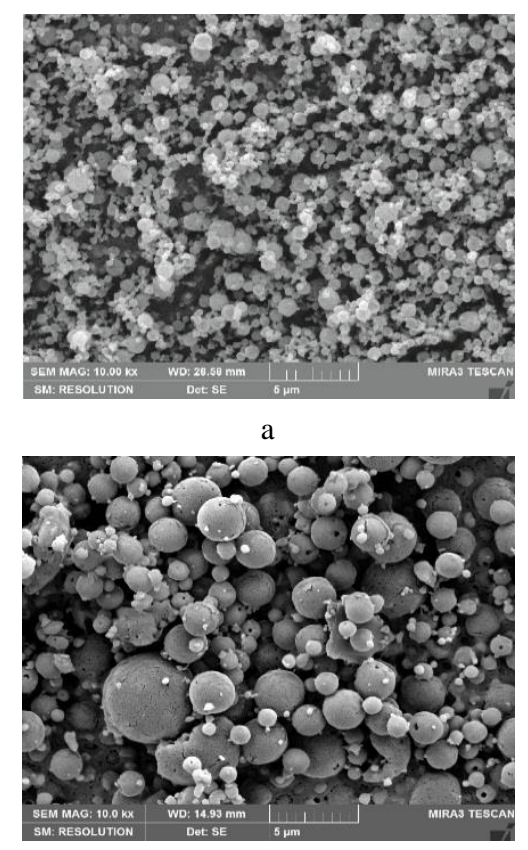

b

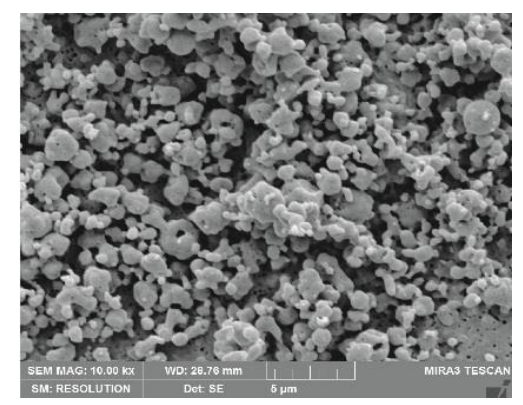

c

Fig. 3. $\mathrm{CL}-20$ particles in different solvents: a-acetone; b-ethyl acetate; $c$-methyl acetate1

\subsubsection{Concentration}

To study the effect of concentration, acetone was used as the solvent, the temperature was $75^{\circ} \mathrm{C}$, and the concentrations were $20 \%, 10 \%, 5 \%$, and $2 \%$, respectively. SEM was used to characterize the morphology of CL-20 samples. The results are shown in Fig. 5.

As shown in Fig. 5, the CL-20 particle size decreases as the decreasing of concentration. However, when the concentration is less than $5 \%$, there is little effect on the particle size of $\mathrm{CL}-20$. The reason was as follows: When the concentration was $20 \%, 10 \%, 5 \%$, the change trend of $\mathrm{CL}-20$ particle size conformed to the trend of particle size change under the ideal spray drying model. In the ideal model, the relationship between the diameter and concentration of explosive particles is:

$d=D(C / \rho)^{1 / 3}$, where $\mathrm{d}$ is the explosive particle size; $D$ is the droplet size; $C$ is the solution concentration; $\rho$ is the explosive crystal density.

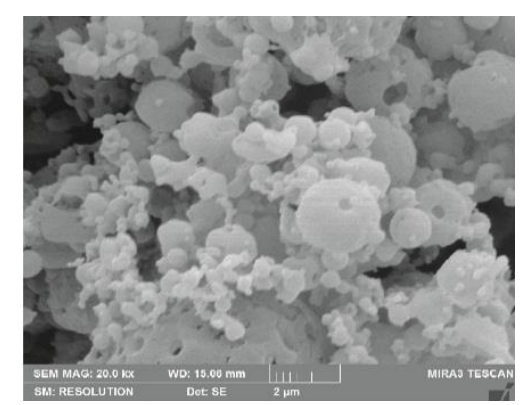

a

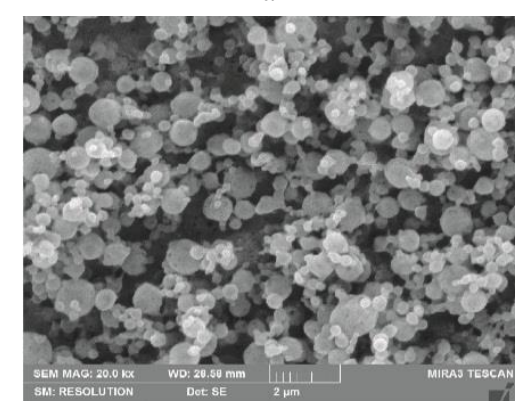

b

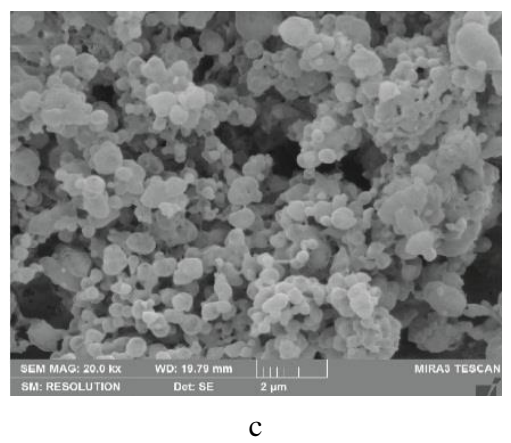

Fig. 4. $\mathrm{CL}-20$ particles in different temperature: $\mathrm{a}-60^{\circ} \mathrm{C}$; $\mathrm{b}-75^{\circ} \mathrm{C} ; \mathrm{c}-90^{\circ} \mathrm{C}$

In this study, the change in particle size was not significant when the concentration was less than $5 \%$. The reason was that the separator could not effectively separate particles which were too small, causing that the small particles were drawn away with the air flow.

In summary, the best process for preparation of ultrafine $\mathrm{CL}-20$ by spray evaporation method is as follows: The $\mathrm{CL}-20$ solution with a concentration of $5 \%$ was spray-evaporated at $75^{\circ} \mathrm{C}$, where acetone was used as a solvent, to obtain an excellent $\mathrm{CL}-20$.

The CL-20 obtained under the optimum condition and raw $C L-20$ are shown in Fig. 6. The morphology of raw $\mathrm{CL}-20$ is complex, with many crystal faces, sharp edges and corners, and particle sizes between 50 and $100 \mu \mathrm{m}$. The nano $C L-20$ has a uniform particle size, a spherical shape, a smooth surface, a particle size of about $300 \mathrm{~nm}$, and good dispersibility.

\subsection{Particle size distribution of nano $C L-20$}

The particle size distribution of $\mathrm{CL}-20$ under optimum conditions was tested by a laser particle size analyzer. The test results are shown in Fig. 7. 


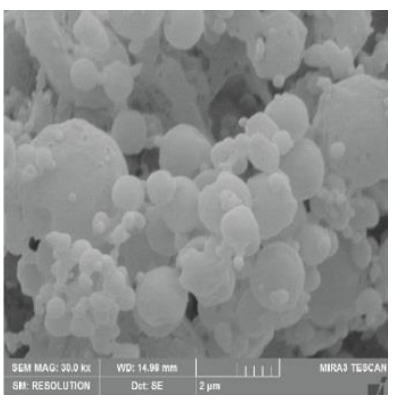

a

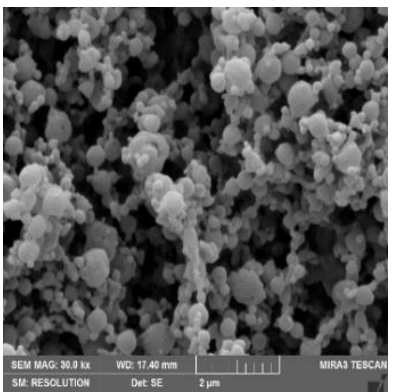

$\mathrm{c}$

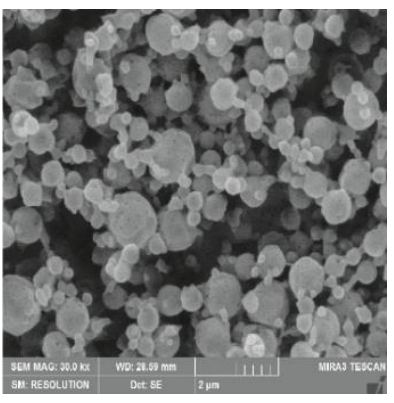

b

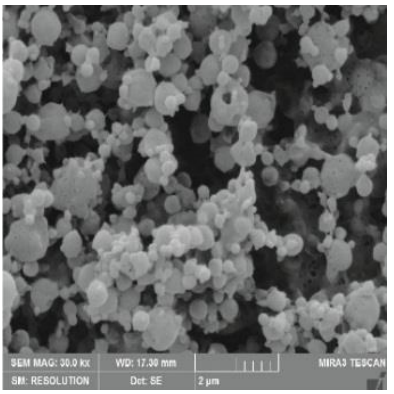

d
Fig. 5. CL-20 particles in different concentration: a-20\%; $\mathrm{b}-10 \% ; \mathrm{c}-5 \% ; \mathrm{d}-2 \%$

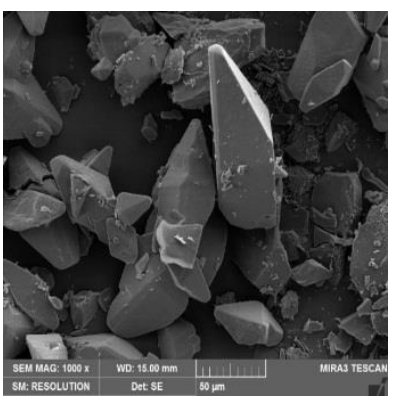

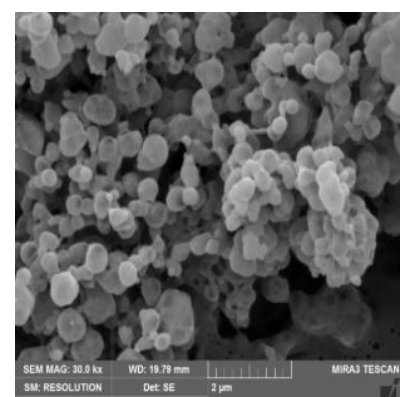

b
Fig. 6. Images: $a-$ raw $C L-20 ; b-$ nano $C L-20$

From Fig. 7 a, it can be seen that the effective diameter of the nano $\mathrm{CL}-20$ is 322 . $1 \mathrm{~nm}$, the particle size distribution is narrow, and it was more consistent with b. (From Fig. 7 b, the average size and particle size distribution of $\mathrm{CL}-20$ are calculated by means of counting more than 400 particles from the obtained SEM images via the statistics of the Nano Measurer software.)

\subsection{XRD analysis}

XRD was used to evaluate raw $\mathrm{CL}-20$, and nano CL-20. Fig. 8 presents observed patterns. By using MDI Jade 9 and PDF 2009 software, crystal form of raw CL - 20 is identified as $\varepsilon$-type, and the nano $\mathrm{CL}-20$ was identified as $\beta$-type. The nano $C L-20$ peak height is significantly reduced, and the peak shape is also broadened. This is due to the reduction in particle size after refinement, and the intensity of the diffraction peak would gradually decrease or even disappear as the particle size decreased.

\subsection{Thermal decomposition characterization}

DSC thermographs of raw and nano CL-20 samples are shown in Fig. 9. It can be seen that compared with that of raw $\mathrm{CL}-20$, the exothermic peak temperature of nano
$\mathrm{CL}-20$ decreases by $5.97^{\circ} \mathrm{C}, 5.88^{\circ} \mathrm{C}$, and $5.53^{\circ} \mathrm{C}$ at $5{ }^{\circ} \mathrm{C} / \mathrm{min}, 10{ }^{\circ} \mathrm{C} / \mathrm{min}, 20^{\circ} \mathrm{C} / \mathrm{min}$, respectively.

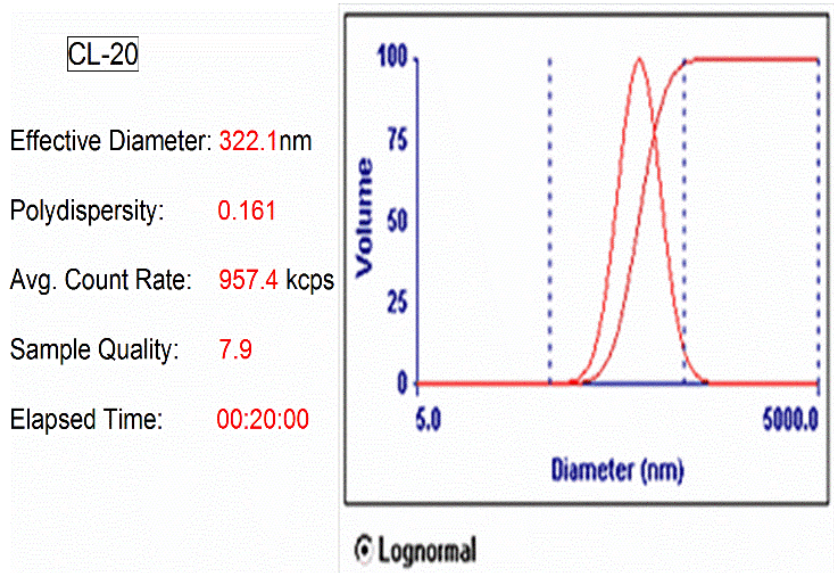

a

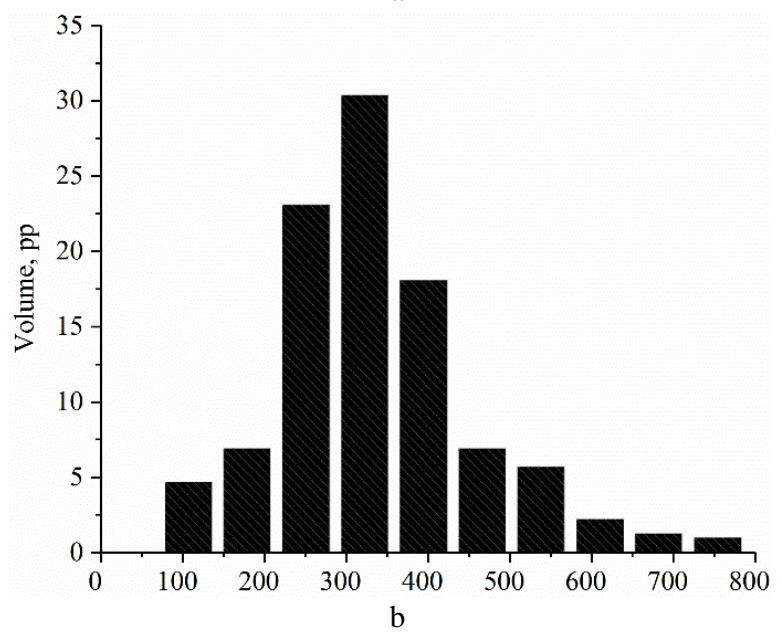

Fig. 7. The particle size distribution of $C L-20$ : $a-$ the effective diameter of the nano $\mathrm{CL}-20 ; \mathrm{b}-$ the average size and particle size distribution of $\mathrm{CL}-20$

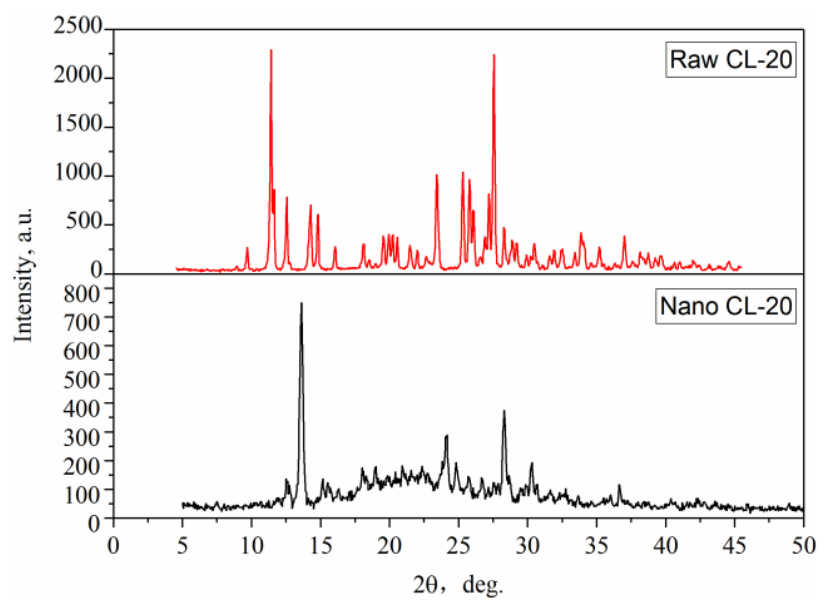

Fig. 8. XRD patterns of samples: Raw $C L-20$, Nano $C L-20$

The results can be explained by the fact that the surface energy, the capacity of heat transmission and the atomic vibration capacity of nano powders are higher, which leads that the molecules are more active to decompose at lower temperature [23].

According to the data from Fig. 9, Kissinger formula (Eq. 2) [24] and Rogers formula (Eq. 3) [25] were used to 
calculate the activation energy $\left(E_{a}\right)$ and the frequency factors (A) of raw $C L-20$ and nano $C L-20$. The results are shown in Table 2.

$\ln \left(\frac{\beta}{T_{p}^{2}}\right)=\ln \left(\frac{A R}{E_{a}}\right)-\frac{E_{a}}{R T_{p}}$

$A=\frac{E_{a} \beta}{R T_{P}^{2}} \exp \left(\frac{E_{a}}{R T_{p}}\right)$

where $\beta$ is the heating rate in $\mathrm{K} \cdot \mathrm{min}^{-1} ; T_{p}$ is the decomposing peak temperature at $\beta$ in $\mathrm{K} ; A$ is the frequency factor; $E_{a}$ is the apparent activation energy in $\mathrm{J} \cdot \mathrm{mol}^{-1} ; R$ is the gas constant, $8.314 \mathrm{~J} \cdot \mathrm{mol}^{-1} \mathrm{~K}^{-1}, K$ is the decomposition rate constant at $T$.
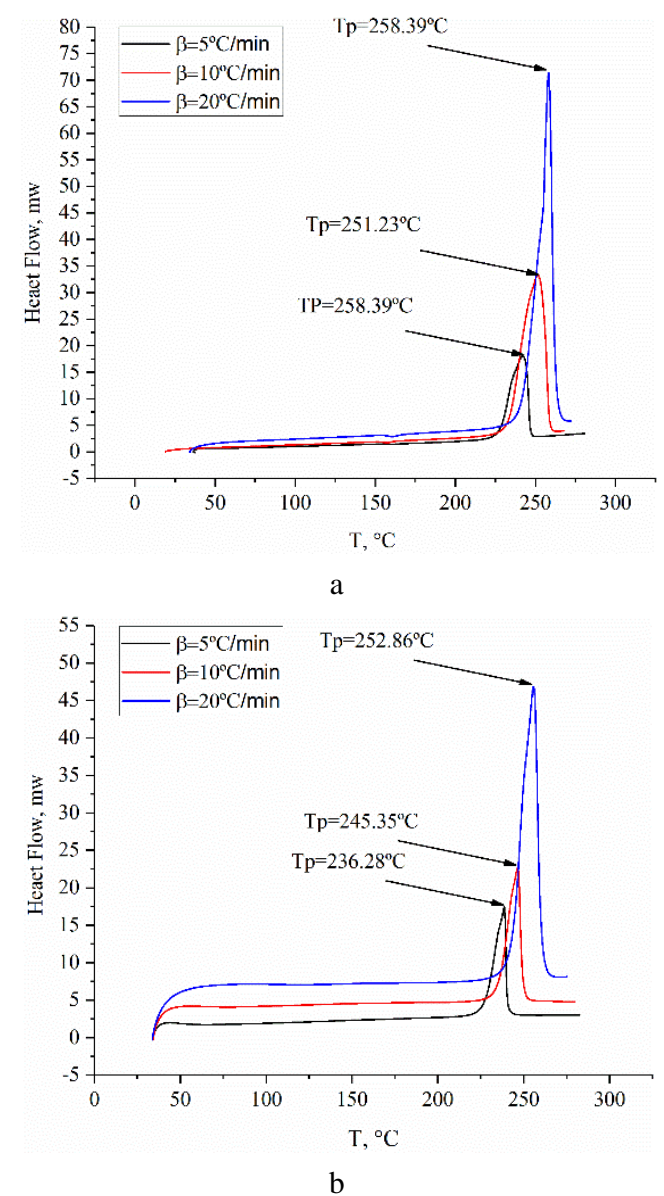

Fig. 9. DSC curves: $a-$ Raw $C L-20 ; b-N a n o ~ C L-20$

Thermal stability is defined as the capability to maintain the characterization about chemical properties during the change of thermal. It can be described by critical explosion temperature $\left(T_{b}\right)$, which can be calculated by Eq. 4 and Eq. 5.

$T_{p i}=T_{p 0}+b \beta_{i}+c \beta_{i}^{2}$

$T_{b}=\frac{E_{a}-\sqrt{E_{a}^{2}-4 \mathrm{RE}_{a} T_{p 0}}}{2 R}$

where $\beta_{i}$ is the heating rate in $\mathrm{K} \cdot \mathrm{min}^{-1} ; T_{p i}$ is the decomposing peak temperature at $\beta_{i}$ in $\mathrm{K} ; T_{p 0}$ is the peak temperature when $\beta$ is zero in $\mathrm{K} ; \mathrm{b}$ and $\mathrm{c}$ are constants; $T_{b}$ is the critical explosion temperature in $\mathrm{K} ; E_{a}$ is the apparent activation energy in $\mathrm{J} \cdot \mathrm{mol}^{-1} ; R$ is the gas constant, 8.314 $\mathrm{J} \cdot \mathrm{mol}^{-1} \mathrm{~K}^{-1}$.
It could be illustrated that the thermal sensitivity of nano $C L-20$ was higher than raw $C L-20$. Due to the decreasing of the particle size, its specific area was increased gradually, and the heating area and reaction activity of the particles would be increased.

Table 2. Thermal decomposition kinetic parameters and explosion critical Temperature data of raw $\mathrm{CL}-20$ and nano $\mathrm{CL}-20$

\begin{tabular}{|c|c|c|c|c|}
\hline Sample & $\begin{array}{c}\mathrm{Ea}, \\
\mathrm{KJ} \cdot \mathrm{mol}^{-1}\end{array}$ & $\mathrm{Lg}(\mathrm{A} / \mathrm{S}-1)$ & $T_{\mathrm{p}} 0,{ }^{\circ} \mathrm{C}$ & $T_{\mathrm{b}},{ }^{\circ} \mathrm{C}$ \\
\hline Raw CL-20 & 185 & 18.4 & 229.65 & 232.16 \\
\hline Nano CL-20 & 172 & 16.8 & 225.41 & 227.93 \\
\hline
\end{tabular}

\subsection{Mechanical sensitivity characterization}

Impact sensitivity tests were performed on raw CL-20, nano CL -20 and Table 3 provides the test results. Nano CL-20 demonstrates a remarkable decrease in impact sensitivity in comparison with raw $\mathrm{CL}-20$. Drop height of nano CL-20 increases by $15.7 \mathrm{~cm}$ compared with raw $C L-20$. Result suggested that the impact sensitivity of nano $C L-20$ is reduced obviously. This can be contacted with the "hot spots" theory. The surface of raw CL-20 is rough relatively, the distribution range of particle size is large and the edges of crystal are obvious, which was easy to form hot spots under impact stimulus. The particles of the nano $C L-20$ are sphere with reduced size and there is no agglomeration, so the hot spots are not easy to form. When nano particles were under impact stimulus, the probability to form "hot spots" was reduced, which led to lower impact sensitivity.

Table 3. Impact sensitivity of raw $\mathrm{CL}-20$ and nano $\mathrm{CL}-20$

\begin{tabular}{|c|c|c|}
\hline Sample & $\mathrm{H}_{50}, \mathrm{~cm}$ & Standard deviation $S, \mathrm{~cm}$ \\
\hline Raw CL-20 & 13.0 & 0.047 \\
\hline Nano CL-20 & 33.5 & 0.034 \\
\hline
\end{tabular}

\section{CONCLUSIONS}

1. The $\mathrm{CL}-20$ nanoparticles with fine morphology were prepared by spray evaporation method. The particle size of the nano CL-20 was about $320 \mathrm{~nm}$ and the crystal type was $\beta$. The effect of different condition on the result of experiment was discussed in this paper.

2. The activation energy $(E \mathrm{a})$ and the frequency factors (A) of the CL-20 obtained were lower than those of raw $\mathrm{CL}-20$, and the thermal stability of the nano $\mathrm{CL}-20$ was lower than that of raw $\mathrm{CL}-20$.

3. From the results of impact sensitivity test, the impact sensitivity of nano $\mathrm{CL}-20$ was reduced obviously. The $\mathrm{H} 50$ of the $\mathrm{CL}-20$ obtained was higher than raw CL- 20 by $15.7 \mathrm{~cm}$.

\section{Acknowledgments}

The authors would like to thank the Advantage Disciplines Climbing Plan of Shanxi Province for supporting this work.

\section{REFERENCES}

1. Bolton, O., AMatzger, A.J. Improved Stability and Smart Material Functionality Realized in an Energetic Cocrystal Angewandte Chemie 123 (38) 2011: pp. 9122 - 9125. 
http://dx.doi.org/10.1002/ange.201104164

2. Urbelis, J.H., Young, V.G., Swift, J.A. Using Solvent Effects to Guide the Design of a CL-20 Cocrystal Crystengcomm 17 (7) 2015: pp. 1564-1568. http://dx.doi.org/10.1039/C4CE02285H

3. Urbelis, J.H., Swift, J.A. Solvent Effect on the Growth Morphology and Phase Purity of CL-20 Crystal Growth \& Design 14 (4) 2014: pp. $1642-1649$. http://dx.doi.org/10.1021/cg401774s

4. Nielsen, A.T., Nissan, R.A., Vanderah, D.J., Coon, C.L., Gilardi, R.D., $\quad$ George, C.F. $\quad$ Flippen-Anderson, J. Polyazapolycyclics by Condensation of Aldehydes with Amines. 2. Formation Of 2, 4, 6, 8, 10, 12-Hexabenzyl2,4,6,8,10,12-Hexaazatetracyclo[5. 5. 0. 05. 9.03,11] Dodecanes from Glyoxal and Benzylamines Journal of Organic Chemistry 21 (5) 1990: pp. 1459-1466. https://doi.org/10.1002/chin.199032201

5. An, C.W., Li, F.S., Wang, J.Y., Guo, X.D. Surface Coating of Nitroamine Explosives and its Effect on The Performance of Composite Modified Double-Base Propellants Journal of Propulsion and Powder 28 (2) 2012: pp. 444-448. https://doi.org/10.2514/1.B34061

6. Nair, U.R., Asthana, S.N., Rao, A.S., Gandhe, B.R. Advances in High Energy Materials Defence Science Journal 60 (2) 2010: pp. 137-151. https://doi.org/10.14429/dsj.60.327

7. Xing, X.L., Zhao, F.Q., Ma, S.N., Xu, S.Y., Gao, H.X., Hu, R.Z. Thermal Decomposition Behavior Kinetics and Thermal Hazard Evaluation of CMDB Propellant Containing CL -20 by Microcaloimetry Journal of Thermal Analysis and Calorimetry 110 (3) 2011: pp. 1451-1455. https://doi.org/10.1007/s10973-011-2026-3

8. Divekar, C.N., $\quad$ Sanghavi, R.R., Nair, U.R., Chakraborthy, T.K., Sikder, A.K., Singh, A. ClosedVessel and thermal studies on Triple-Base Gun Propellants Containing CL-20 Journal of Propulsion and Powder 26 (1) 2010: pp. 120-124.

https://doi.org/10.2514/1.40895

9. Yan, Q.L., Zeman, S., Elbeih, A. Recent Advances in Thermal Analysis and Stability Evaluation of Insensitive Plastic Bonded Explosives Thermochimica Acta 537 2012: pp. $1-12$. https://doi.org/10.1016/j.tca.2012.03.009

10. Samudre, S.S., Nair, U.R., Gore, G.M., Sinha, R.K., Sikder, A.K., Asthana, S.N. Studies on an Improved Plastic Bonded Explosives for Shaped Charges Propellants, Explosives, Pyrotechnics 34 (2) 2009: pp. 145-150. https://doi.org/10.1002/prep.200800036

11. Lan, Y., Jiang, X.B, Guo, X.Y., Ren, H., Jiao, Q.J. Effects of Binders and Graphite on The Sensitivity of $\varepsilon$-HNIW Journal of Thermal Analysis and Calorimetry 112 (3) 2012: pp. $1343-1349$.

https://doi.org/10.1007/s10973-012-2679-6

12. Guo, C., Zhang, H., Wang, X.C., Xu, J.C., Liu, Y., Liu, X.F., Huang, H., Sun, J. Crystal Structure and Explosive Performance of a New CL-20/Caprolactam Cocrystal. Journal of Molecular Structure 1048 2013: pp. $267-273$.

https://doi.org/10.1016/j.molstruc.2013.05.025
13. Hoffman, D.M., Fatigue of LX-14 and LX-19 Plastic Bonded Explosives Journal of Energetic Materials 18 (1) 2000: pp. 1-27. https://doi.org/10.1080/07370650008216110

14. Donald, A., Geiss, J. Additional Characterization of High Performance CL-20 Formulations Proceeds of 30th International Annual Conference of ICT 1999: pp. 167-180.

15. Sivabalan, R., Gore, G.M., Nair, U.R., Saikia, A., Venugopalan, S., Gandhe, B.R. Study on Ultrasound Assisted Precipitation of $\mathrm{CL}-20$ and its Effect on Morphology and Sensitivity Journal of Hazardous Materials 139 (2) 2011: pp. 199-203. https://doi.org/10.1016/j.jhazmat.2006.06.027

16. Wang, J.Y., Li, J.L., An, C.W., Xu, W.Z., Li, X.D. Study on Ultrasound and Spray-Assisted Precipitation of CL-20 Propellants Explosives, Pyrotechnics 37 (6) 2012: pp. $670-675$. https://doi.org/10.1002/prep.201100088

17. Bayat, Y., Zarandi, M., Zarei, M., $\quad$ Soleyman, R., Zeynali, V. A Novel Approach for Preparation of CL-20 Nanoparticles by Microemulsion Method Journal of Molecular Liquids 193 (5) 2014: pp. 83-86. https://doi.org/10.1016/j.molliq.2013.12.028

18. Guo, X.D., Ou, G., Liu, J., Li, Q., Wang, L.X., Gu, Z.M., Li, F.S. Massive Preparation of Reduced-Sensitivity Nano $\mathrm{CL}-20$ and its Characterization Journal of Energetic Materials 33 (1) 2015: pp. 24-33. https://doi.org/10.1080/07370652.2013.877102

19. Suh, W.H., Suslick, K.S. Magnetic and Porous Nanospheres from Ultrasonic Spray Pyrolysis Journal of the American Chemical Society 127 (4) 2005: pp. 12007-12010.

https://doi.org/10.1021/ja050693p

20. Kim, J.M., Shin, M.S., Kim, J.K., Kim, H.S., Koo, K.K. Evaporation Crystallization of RDX by Ultrasonic Spray Industry \& Engineering Chemistry Research 50 (21) 2014: pp. $12186-12193$.

https://doi.org/10.1021/ie201314r

21. Spitzer, D., Baras, C., Schafer, M.R., Ciszek, F., Siegert, B. Continuous Crystallization of Submicrometer Energetic Compounds Propellants Explosives Pyrotechnics 36 (1) 2015: pp. 65-74. https://doi.org/10.1002/prep.200900002

22. Chinese Commission of Science and Technology and Industry for National Defense. Explosive test method. Chinese NationalMilitaryStandardGJB/772A-97, 1997.

23. Zhang, C.Y., Peng, Q., Wang, L.Y., Wang, X.C. Thermal Sensitivity of HMX Crystals and HMX-Based Explosives Treated under Various Conditions Propellants Explosives Pyrotechnics 35 2010: pp. 561-566. https://doi.org/10.1002/prep.200800010

24. Kissinger, H.E. Reaction Kinetics in Differential Thermal Analysis Analytical Chemistry $29(11)$ 1957: pp. $1702-1706$. https://doi.org/10.1021/ac60131a045

25. Zhang, T.L., Hu, R.Z., Xie, Y., Li, F.P. The Estimation of Critical Temperature of Thermal Explosion for Energetic Materials Using Non-Isothermal DSC Thermochim Acta 244 1994: pp. $171-176$. https://doi.org/10.1016/0040-6031(94)80216-5

(c) Xu et al. 2021 Open Access This article is distributed under the terms of the Creative Commons Attribution 4.0 International License (http://creativecommons.org/licenses/by/4.0/), which permits unrestricted use, distribution, and reproduction in any medium, provided you give appropriate credit to the original author(s) and the source, provide a link to the Creative Commons license, and indicate if changes were made. 